\title{
Renta Básica Incondicional y Economía Social: un intento de relación ${ }^{1}$
}

\author{
Julen BoLlain \\ Doctorando en la Universidad del País Vasco / Euskal Herriko Unibertsitatea
}

DOI: $10.1387 /$ reves. 17534

Fecha de entrada: 11/01/2016

Fecha de aceptación: 26/02/2016

\begin{abstract}
Sumario: 1. Introducción. 2. ¿Qué es la Economía Social? Propiedades y objetivos de la Economía Social. 3. Propiedades y objetivos de la Renta Básica Incondicional. 4. La Renta Básica Incondicional y la Economía Social ante el individualismo liberal. 5. La Economía Social y la Renta Básica Incondicional frente al intervencionismo del Estado. 6. ¿'Necesidad de participar activamente en la economía? 7. Trabajo, Economía Social y Renta Básica Incondicional. 8. Conclusión. 9. Bibliografía.
\end{abstract}

\section{Resumen:}

Durante los últimos años ha habido un creciente interés por ciertos términos económicos hasta hace poco tiempo desconocidos. Entre ellos se encuentran la Economía Social y la Renta Básica Incondicional, conceptos que durante su intensa historia no han tenido un camino sencillo para calar en la sociedad. La Economía Social ha tenido que lidiar con la hegemonía del neoliberalismo, un modelo económico establecido desde finales de la década de 1970 y principios de 1980 que, a pesar de las múltiples crisis cíclicas que han sacudido la economía mundial, parece perdurar en el tiempo. En cuanto a la Renta Básica Incondicional se refiere, la visión general ha sido que el hecho de dar dinero sin condiciones ni obligaciones promueve la holgazanería, la dependencia y que es enormemente costoso. Este artículo intenta asociar ambas ideas analizándolas conjuntamente para observar los distintos enfoques que éstas ofrecen desde un mismo punto de partida. Tras examinar los dos conceptos se realiza un intento de relación para así promulgar un nuevo estado de protección social y libertad más allá de los valores individualistas que radican en el neoliberalismo.

\footnotetext{
${ }^{1}$ Este artículo forma parte de una tesis doctoral en curso.
} 


\title{
Palabras clave:
}

Economía Social, Renta Básica Incondicional, neoliberalismo, capitalismo, libertad, individualismo, comunitarismo, republicanismo, cambio social y económico.

\begin{abstract}
:
During the last years there has been a growing interest in some, until recently, unknown economic terms. These terms include the Social Economy and Unconditional Basic Income, concepts that during their intense history have not had an easy way to permeate society. The Social Economy has strongly struggled with neoliberalism's hegemony, a well-established economic model since the late 1970s/early 1980s that, despite many cyclical crisis that have shaken global economy, seems to last over time. As for Unconditional Basic Income is concerned, the general perspective has been that giving money without conditions or duties promotes laziness, dependency and that it is extremely expensive. This article tries to associate these two ideas and analyzing them together examines the different approaches they provide to the same starting point. Once looked at both concepts, a connection attempt is made between them in order to enact a new state of social protection and freedom beyond individualistic values that reside in neoliberalism.
\end{abstract}

\section{Keywords:}

Social Economy, Unconditional Basic Income, neoliberalism, capitalism, freedom, individualism, comunitarism, republicanism, social and economic change.

\section{Claves Econlit:}

J310, J650, 1380

\section{Introducción}

El presente artículo nace desde la necesidad de unir dos conceptos relacionados con la economía que hasta ahora han sido analizados por separado: la renta básica incondicional y la economía social. Para ello, trataremos de analizar puntos importantes para ver los distintos comportamientos que tienen la renta básica incondicional y la economía social, siendo ambos términos, y sobre todo sus conceptos, hasta hace no mucho desconocidos o parcialmente conocidos mediante concepciones erróneas tanto para la clase política como para la mayoría de la clase científica española. Ni qué decir para la ciudadanía.

A pesar de la ignorancia y la incomprensión que ha recaído sobre ellos, el gran auge vivido durante los últimos años tanto por la renta básica incondicional como por la economía social, empujados por la incansable la- 
bor de su cada vez mayor número de defensores y el sentido común, ha hecho que estas dos expresiones estén en el candelero.

$\mathrm{Y}$ no son pocos los motivos para que esto ocurra en un mundo donde gran parte de los valores cívicos y sociales se han destruido por completo en aras de una economía basada en la mercantilización del trabajo y en una visión individualista de la persona. Citando simplemente un ejemplo palpable de la deshumanización existente, tenemos el informe de 2016 que presentaba Oxfam con un título más que sugerente: Una economía al servicio del $1 \%$. En este informe Oxfam (2016) afirma que «el poder y los privilegios se están utilizando para manipular el sistema económico y asi ampliar la brecha, dejando sin esperanza a cientos de millones de personas pobress. ${ }^{2} \mathrm{Y}$ sí, habrá gente que piense que esto no es sino una exageración pero, lamentablemente, la tiranía del capitalismo (al menos del actualmente existente), mata (Papa Francisco I, 2013). Y es que hoy en día sigue siendo noticia que el barril de petróleo esté en mínimos, pero no así que nuestros conciudadanos mueran de hambre o frío.

Al fin y al cabo, tal y como afirma Coraggio (2011), treinta años regidos por el neoliberalismo han evidenciado el carácter estructural de la cuestión social propia del modelo económico capitalista: una merma masiva del empleo, la degradación de los salarios y de los derechos sociales y la enorme concentración de la riqueza tal y como el informe de Oxfam (2016) constata.

Opinamos que la economía social es el método para combatir la deshumanización mediante los valores cívicos que promulga, y al mismo tiempo tenemos el firme criterio de que también comparte propósitos con la renta básica incondicional, la cual tiene como objetivo principal, en expresión de algunos de sus defensores, garantizar la existencia material de todos los ciudadanos. Y sí, como tal y como comentaremos en capítulos posteriores, la palabra que utilizamos para definir el objetivo de la renta básica incondicional es ciudadano frente a individuo. Por eso, creemos conveniente y nos parece que es el momento adecuado para analizar este modelo económico y esta medida económica en conjunto, pudiendo así crear un intento de relación entre la economía social y la renta básica incondicional.

\section{2. ¿Qué es la Economía Social? Propiedades y objetivos de la Economía Social}

La economía social o tercer sector se puede considerar el cajón de sastre donde se ubican aquellas formas organizacionales que no tienen cabida en

2 Oxfam (2016). Una Economía al Servicio del 1\%. Disponible en: https://www.oxfam. org/sites/www.oxfam.org/files/file_attachments/bp210-economy-one-percent-tax-havens180116-es_0.pdf 
el sector mixto y en las dos realidades económicas mayoritarias hoy en día: el sector público y el sector capitalista (Barea, 1990).

Como decía Michelsen (1992), la economía social, a diferencia de aquellos sectores gobernados por fuerzas fuera del alcance directo del ciudadano, introduce la posibilidad de un cambio en las relaciones existentes entre el ciudadano y el proceso económico de producción de bienes y servicios. De este modo lo que pretende es que el ciudadano, mediante su condición de miembro, tenga la posibilidad de participar directamente en definir los objetivos y la gestión de un agente bajo los estandartes de la economía social.

Siguiendo con Barea (1990) vemos como la economía social abarca aquellas empresas que ejerzan en el mercado con el fin de producir, asegurar, financiar o distribuir bienes o servicios, pero en las cuales la repartición de beneficios no esté directamente relacionada con el capital que anteriormente haya aportado cada miembro y que las decisiones se tomen teniendo en cuenta la premisa de 1 miembro 1 voto, no estando éstas supeditadas al capital aportado por cada socio. Basándonos en esta definición, podríamos resumir la economía social en 5 características principales:

i. La economía social, a diferencia de lo que algunos puedan pensar, está totalmente desligada de la economía pública.

ii. Los agentes englobados en la economía social sí pueden obtener beneficios mediante la actividad productiva.

iii. Es necesario un capital para desarrollar todas aquellas actividades en las que el agente esté inmerso (véanse actividades de producción, de comercialización, de distribución, etc.).

iv. Principio de «1 miembro, 1 voto». La toma de decisiones, no está subordinada al capital, sino a los socios propietarios de la empresa.

v. Para que un agente pueda pertenecer a la economía social, no puede existir en su seno ninguna correlación, ya sea directamente proporcional o de otro tipo, entre el capital aportado por cada socio y el beneficio repartido.

Una vez hemos anotado las principales características que identifican a la economía social, procedemos a definir dos propiedades genéricas de gran relevancia que la economía social ostenta y que influirán en la asignación, acumulación, distribución y regulación económica (Carpi, 1997).

La primera de estas propiedades es referente a la condición de miembro del ciudadano, donde se introduce un nuevo modo de influir sobre el proceso económico. De esta manera y citando a Hirschman (1970), podemos afirmar que la implicación del miembro es diferente a la salida, (condición propia del mercado) y a la voz (condición propia de lo público), intervenciones que bajo en el modelo económico dominante hoy en día, en mayor o menor medida, residen en el seno de los ciudadanos. 
La segunda propiedad se basa en la cercanía entre la economía y la ciudadanía. Una cercanía que parece desaparecida en los últimos años, como si hubiera sido robada por los poderes económicos y los ciudadanos no tuviéramos nada que decir ni aportar a las decisiones económicas que acaecen en nuestro entorno. Así, la economía social invita a la implicación y crea una estrecha conexión entre la economía y la sociedad civil mediante la participación (Michelsen, 1992).

Estas dos cualidades evidencian claramente su potencial socializador y de activación social que en palabras de Hirschman (1987) una vez más, se ha demostrado sobradamente en las múltiples experiencias llevadas a cabo en Latinoamérica.

Tras haber analizado las propiedades de la economía social, observamos cómo ésta considera como objetivos la implicación de la ciudadanía en la definición de objetivos y gestión de los agentes pertenecientes a la misma y el servicio a los miembros o a la colectividad antes que al beneficio. Bien podemos afirmar que éstos difieren de aquellos objetivos que radican en la renta básica incondicional y los cuales serán analizados en el siguiente capítulo, donde estudiaremos cómo actúa la renta básica incondicional en el seno de la ciudadanía mediante sus propiedades y objetivos.

\section{Propiedades y objetivos de la Renta Básica Incondicional}

La renta básica incondicional no tiene el objetivo de la implicación de la ciudadanía en la toma de decisiones al que la economía social hace referencia. La renta básica incondicional tiene como objetivo la libertad individual, de manera universal e incondicional, estableciendo la garantía del derecho a la existencia (Casassas y Raventós, 2011).

Pero, ¿qué es la renta básica incondicional? La misma Red Renta Básica (http://www.redrentabasica.org/rb/) nos ofrece su definición al afirmar que «es un ingreso pagado por el estado, como derecho de ciudadanía, a cada miembro de pleno derecho o residente de la sociedad». ${ }^{3}$ De esta definición podemos extraer sus principales características:

i. La renta básica incondicional es un ingreso pagado por el estado como derecho de ciudadanía.

ii. La renta básica incondicional se percibe independientemente de que un ciudadano quiera o no trabajar de forma remunerada.

3 Red Renta Básica (s.a.). ¿Qué es la RB? Disponible en: http://www.redrentabasica.org/rb/ que-es-la-rb/ 
iii. Para que un ciudadano pueda percibir la renta básica incondicional no se tienen en consideración otras posibles fuentes de renta, es decir, si una persona es rica o pobre.

iv. La renta básica incondicional se percibe de igual manera independientemente de con quién se conviva.

Dicho con otras palabras, la renta básica incondicional es una asignación monetaria pagada por el estado de manera universal, incondicional e individual. El principio de universalidad y el principio de individualidad constatan que ésta es percibida por toda la población y el principio de incondicionalidad se basa en que se concibe como derecho ciudadano no dependiente de condiciones previas.

Además de estos tres principios, existe una condición necesaria para garantizar que la renta básica incondicional cumpla con su objetivo principal de garantizar la existencia material de la ciudadanía (Arcarons et al., 2014) y es que ésta se rija bajo el principio de la suficiencia. Con este principio se asegura que la asignación monetaria percibida por el ciudadano sea suficiente para garantizar la existencia del perceptor.

Por lo tanto, podemos apreciar como la renta básica incondicional actúa en la economía de una manera distinta a como lo hace la economía social, garantizando la existencia material de la ciudadanía y dotando de unos poderes de enorme magnitud al ciudadano. En otras palabras: dota de libertad a los ciudadanos a través del derecho ciudadano a la «no-dominación».

Quijote: «La libertad, Sancho, es uno de los más preciados dones que a los hombres dieron los cielos (...) iventuroso aquél a quien el cielo dio un pedazo de pan, sin que le quede obligación de agradecerlo a otro que al mismo cielo!'.

La dominación (Raventós y Bertomeu, 2006) no es compatible ni con la libertad política ni con el ejercicio de ciudadanía debido al dominium que los propietarios (aquéllos que ejercen el control sobre el recurso poseído) y los ricos ejercen sobre aquellos ciudadanos que no son complemente libres. Por ello, Raventós y Bertomeu (2006) afirmaron que la ciudadanía plena no es comprensible si no existe la independencia material o un "control» sobre el conjunto de oportunidades. Los autores republicanos demócratas a finales del siglo xVIII y principios del xIX consideraron dos opciones para que se materializara el concepto de libertad en el que la renta básica incondicional se ha fundamentado posteriormente. La primera era una sociedad basada en la universalización de la pequeña propiedad agraria por la que abogaron Jefferson o Robespierre, y la segunda era un derecho de existencia social públicamente garantizado que argüía 
Robespierre (Domenech, 2007) o un ingreso material incondicional asignado a todos los ciudadanos por el mero hecho de serlo por el que promulgaba Tom Paine (1796). Este ingreso material incondicional al que hacía referencia Tom Paine se denominaría hace más de dos siglos renta básica garantizada o, tal y como hoy en día se conoce un ingreso material incondicional asignado a todos los ciudadanos por el hecho de serlo, renta básica incondicional.

\section{La Renta Básica Incondicional y la Economía Social ante el individualismo liberal}

Allá por 1987 le ofrecieron a Amitai Etzioni (Colonia, Alemania 1929) ser profesor visitante en Harvard Business School, quedándose perplejo cuando un grupo de profesores le vienen a decir que no les hable sobre valores familiares, que ellos son progresistas (Etzioni, 2013). De esta manera dejaron latente estos profesores que se comprendía «el individualismo como paradigma para enfocar el comportamiento económico" en la citada universidad, donde hablar de valores se interpretaba como si de un punto de vista no «liberal» se tratara y por ende, fuera de lugar. A raíz de esto Etzioni escribiría The Moral Dimension. Toward a New Economy (1988), donde negando tres ideas del concepto individualista sintetiza su pensamiento comunitarista. En este pensamiento comunitarista y a diferencia de «una visión de la sociedad como en cierta forma constituida por individuos, los que la constituyen teniendo en vista fines primariamente individuales ${ }^{4}$ contemplaba definiendo el individualismo, afirma que no todas las elecciones de los hombres pretenden maximizar beneficios, no siempre elegimos racionalmente y no elegimos solos, sino grandemente influidos por los grupos a los que pertenecemos.

Basándose en la solidaridad y en el comunitarismo que se opone a la «atomización» que radica en el pensamiento liberal, nace la economía social. La economía social se identifica con una serie de experiencias organizacionales (França Filho, 2002) basadas en el comunitarismo (França y Dzimira, 2000), y teniendo como uno de sus objetivos la «finalidad de servicio a los miembros o a la colectividad antes que al beneficio" (Ciriec, 2000). En este principio de la economía social radica un gran lazo que lo ata con la renta básica incondicional y sus fuertes raíces en el republicanismo clásico. Este lazo se puede observar en la misma definición que antes hemos p. 187

4 Taylor, C. (1985). Philosophical Papers II. Cambridge: Cambridge University Press, 
citado de la Red Renta Básica (http://www.redrentabasica.org/rb/), donde se concreta que la renta básica incondicional es un ingreso, pagado por el estado como derecho de ciudadanía a cada miembro de pleno derecho o residente de la sociedad. Se puede apreciar como «los miembros/la colectividad» $\mathrm{o}$ «derecho de ciudadaníalresidente de la sociedad» se hallan en el punto de mira de las definiciones y es ahí donde precisamente radica la importancia de estos dos términos. Por lo tanto podríamos afirmar que una de las grandes diferencias entre la renta básica incondicional y la economía social y el neoliberalismo dominante hoy en día, es que mientras los dos primeros conceptos ven a la sociedad como un conjunto de ciudadanos entrelazados, el segundo ve la sociedad como un conjunto de individuos independientes luchando por sus intereses particulares.

Sin embargo y aunque los dos conceptos vayan más allá del individualismo y de la lucha de todos contra todos por la que aboga el neoliberalismo a la que hacía referencia entre otros Pierre Bourdieu (1998), existen diferencias en el ámbito de actuación que ambos proponen. Por un lado la economía social, aunque su área geográfica de implantación no esté limitada, sí acota su ámbito de actuación a esos miembros de la sociedad que de motu propio decidan participar en ella. La renta básica incondicional, por el contrario, es un derecho que atañe a toda la ciudadanía dentro del espacio geográfico donde se haya implantado por el mero hecho de ser ciudadanos. Su ámbito de actuación no queda circunscrito a una colectividad, sino que el bien común queda justificado como derecho de ciudadanía a toda la población.

Por lo tanto podemos observar como la renta básica incondicional sí cumple su objetivo de garantizar la existencia material a todos los ciudadanos dentro del área geográfica determinado en el cual se implante, pero al mismo tiempo vemos que como medida económica que es, no cambia radicalmente el modelo de producción hoy día existente. La economía social, sin embargo, va creando átomos interrelacionados bajo los parámetros de un mismo modelo económico dentro de una sociedad donde velará por el bienestar de los miembros allí presentes antes que por la maximización del beneficio. El colectivo que habite bajo los estandartes de la economía social, tendrá un modelo productivo distinto al capitalista que se basará en la economía solidaria.

\section{La Economía Social y la Renta Básica Incondicional frente al intervencionismo del Estado}

La economía social plantea que tanto el mercado capitalista, alienante en sí mismo y con poderes capaces de manipular los valores, necesidades y 
formas de socialización, como el estado centralizado, que sustrae poder de la sociedad actuando como un delegado y asumiendo la representación de un bien común nacional, deben ser superados (Coraggio, 2011).

Desde nuestro punto de vista está en lo cierto Coraggio (2011) en su planteamiento cuando afirma que el estado sustrae poder de la sociedad, pero opinamos que habría que matizar su exposición, ya que no necesariamente esa sustracción de poder es negativa. Vemos la sustracción de poder de la sociedad necesaria para la existencia de una justicia en el seno de la sociedad. Una justicia, como la definiría Van Parijs (1996) basada en el maximin de las condiciones materiales, sometidas a satisfacer ciertas limitaciones como el respeto por las libertades fundamentales.

Creemos que el estado es capaz y es el mejor agente a la hora de asumir la representación de un bien común nacional siempre y cuando exista un gobierno que priorice los intereses de la sociedad en su conjunto. Dicho esto, no somos de la opinión de que el estado deba ser superado, sino convertido en un estado que asuma la representación del bien común nacional y se sobreponga a la inadaptación de los viejos métodos de gestión social a los del siglo XXI.

Ya finales del siglo Xvir Leibniz es firme defensor del seguro como instrumento de justicia ya que permite reducir la distancia entre el estado social ideal (gobernado por la justicia distributiva) y el estado de derecho (erguido sobre la justicia conmutativa). Hobbes también defendería el seguro mutuo obligatorio, oponiéndolo al «estado reductor de incertidumbre» como solución al problema de riesgo. Esta técnica aseguradora no era nueva, pero por primera vez se aplica a principios del siglo XVIII en personas tras haber sido utilizada anteriormente para los bienes y mercancías (Rosanvallon, 1995).

Fueron años malos para el seguro aplicado a las personas ya que aún generaba una cierta duda al temer que pudiera socavar el sentimiento de responsabilidad y entrañar comportamientos inmorales. Tuvo que pasar un siglo, hasta finales del siglo XIX, para que esta técnica fuera moralmente aceptable y considerara como una respuesta adecuada a la gestión de los problemas sociales, en parte porque el sentimiento de responsabilidad no había sido eficaz a la hora de paliar la miseria (Rosanvallon, 1995). Después de las fuertes luchas comenzadas en la revolución industrial, en el último tercio del siglo XIX el movimiento obrero volvió a tomar una dirección reivindicativa y exigió a los poderes públicos que fueran los empresarios quienes pagaran por las consecuencias dañosas del sistema fabril, en especial por los accidentes de trabajo. Así, comenzaron a incorporarse los seguros en los distintos países europeos, llegando a aprobarse en 1900 en España lo que podríamos denominar la primera ley de Seguridad Social española: la ley de accidentes de trabajo de 30 de enero de 1990. Sin em- 
bargo, en España no será hasta la segunda república cuando se dé la obligatoriedad del aseguramiento por parte del empresario junto al principio de automaticidad de las prestaciones mediante la ley de 4 de julio de 1932 (Caracuel y Fernández, 1999).

Los seguros, la Seguridad Social, han sido durante más de un siglo una gran herramienta para rebajar el riesgo de los trabajadores pero, podemos observar como hoy en día no es suficiente. Hay que adaptarse a las nuevas épocas, épocas en la que la Seguridad Social ya no solo no consigue dar cobertura a toda la ciudadanía en su conjunto, sino tampoco a aquéllos miembros de la ciudadanía que han cotizado durante años. Noticias publicadas en Espańa recientemente nos alertan de que la Seguridad Social española está en verdadero riesgo, donde los ingresos son mucho menores que los desembolsos a realizar y la llamada hucha de las pensiones, al ritmo establecido entre 2012 y 2015, se acabaría en dos ejercicios. Distintos partidos políticos han planteado posibilidades como que ciertas prestaciones se financien directamente a través de impuestos como el IVA o el IRPF y no a través de cotizaciones (Partido Popular) o que se cree un nuevo impuesto «solidario» (Partido Socialista Obrero Español) para así poder costear los gastos de la Seguridad Social (Gómez, 2016). Planteamientos en nuestro punto de vista insuficientes para hacerle frente a la realidad del problema, y es que el Estado no garantiza el derecho de existencia de la ciudadanía. La Seguridad Social es una herramienta que no cumple su objetivo de ofrecer una protección adecuada cuando existen trabajadores que viven por debajo del umbral de la pobreza. Además, el Estado, mediante la Seguridad Social, no tiene en cuenta a toda la ciudadanía en su conjunto, estableciéndose gran parte de la misma fuera de ninguna protección social.

«De todos los derechos, el primero es el de existir. Por tanto, la primera ley social es aquella que garantiza a todos los miembros de la sociedad los medios para existir; todas las demás leyes están subordinadas a esta ley social». (Maximilien Robespierre, 1792)

Creemos firmemente que hay que construir un nuevo modelo de estado donde se garantice el derecho a la existencia material de toda la ciudadanía. Un estado donde no sea el simple trabajo remunerado el que dignifique a las personas, sino que la existencia material garantizada por el mero hecho de existir sea la que las dignifique. Un estado, donde la protección social que ofrece la Seguridad Social sea compatible con una renta básica incondicional que garantice la existencia material de todos los ciudadanos y donde tenga una gran cabida la economía social, estableciendo así las prioridades del ciudadano por encima del capital. 


\section{6. ¿Necesidad de participar activamente en la economía?}

La economía social, como hemos comentado anteriormente, tiene como objetivo la implicación del ciudadano, mediante su condición de miembro, en definir directamente los objetivos y la gestión de un agente bajo los estandartes de la economía social (Michelsen, 1992).

Es verdad que la economía social intenta superar la sociedad de mercado en la que vivimos sin dejar atrás los mecanismos mercantiles a través de la "construcción de circuitos de intercambios solidarios entre emprendimientos, de forma de ir configurando otro mercado" ${ }^{5}$, pero al fin y al cabo, la implicación en la misma recae sobre aquéllos que se acojan a su derecho de participar activamente en la economía. ¿Pero, y si el ciudadano no tiene ningún interés en participar activamente en la economía?

Desde nuestro punto de vista, el uso de la libertad personal como derecho de no-participación en la economía no debe ser un problema para que el derecho de existencia y la garantía de los medios para que éste se cumpla en todos y en cada uno de los ciudadanos sea una realidad.

El modelo económico que presenta la economía social sí es un gran paso para que gran parte de los intereses sociales se antepongan dentro de la economía de mercado radical existente hoy en día. A través la economía social, efectivamente, primarían los intereses de las personas por encima de los del capital, primaría el principio de solidaridad dentro del colectivo en vez del principio de individualismo, primaría la democracia organizativa de «una persona un voto» y primaría, por ejemplo, el retorno cooperativo de los beneficios, pero no valdría para garantizar la existencia material de todos los ciudadanos.

¿Qué ocurriría con el surfista que simplemente se dedica a surfear en las playas de Malibú al que Rawls hacía referencia y que no quiere participar activamente en la economía? Rawls (1993) afirmaría que aquél que surfea todo el día en Malibú tendría que buscarse un modo de sustento y que no podría beneficiarse de los fondos públicos. Bajo los parámetros liberales, parece que en aquellos casos donde no exista una reciprocidad en los intercambios se viola el contrato social, al «tomar injustamente ventaja sobre otro». (Elster, 1982). Sin embargo, Van Parijs (1995) afirma que no es necesaria una estricta reciprocidad en los intercambios a la hora de que una sociedad sea justa o no. Para obtener la justicia en una sociedad, volvemos a la tradición republicana por la que varios autores (Pocock, 1975; Skinner, 1992; Pettit, 1999) han abogado y que se basa en que el estado pro-

5 Boulianne, M., Fraisse, L., y Órtiz Roca, H. (2001). La economía solidaria: hacia un modelo renovado de desarrollo. Texto de lanzamiento del taller Economía solidaria. Disponible en: http://base.socioeco.org/docs/doc-1_es.pdf 
mueva la libertad mediante «el ideal de no dominación como la única vara con que medir y juzgar la constitución social y politica de una comunidad». ${ }^{6}$

Por ello opinamos que un cambio desde la economía neoliberal hacia la economía social no sería suficiente para garantizar el ideal de no dominación y por ende, la justicia en una sociedad. Para que así fuere habría que garantizar el derecho a la existencia de la ciudadanía y con el fin de obtenerlo, somos de la firme convicción de que la mejor herramienta sería una renta básica incondicional, dotando de una asignación monetaria a cada ciudadano para que así, quiera o no ser participe e implicarse en la economía basada en el capital, disponga de su existencia material garantizada durante toda su vida y no viva bajo la dominación, incompatible con la libertad política y con el ejercicio de ciudadanía.

\section{Trabajo, Economía Social y Renta Básica Incondicional}

Uno de los más graves problemas que observamos al analizar la economía social es que la superación de la barrera del trabajo como sinónimo de empleo es parcial y, una vez más, como los demás modelos económicos engloba a aquellas organizaciones que encuentran su razón de ser en la producción de bienes y servicios. La economía social, permite la interacción directa entre el ciudadano y el proceso de producción de bienes y servicios (Michelsen, 1992) y, aunque no todos sus logros puedan ser percibidos desde una perspectiva estrictamente económica o tenga una relación muy estrecha con la sociedad, mantiene la ecuación de trabajo igual a empleo activa, añadiendo a la misma el trabajo voluntario.

Pese a que tampoco exista un consenso a la hora de definir qué organizaciones se acoplan dentro de la definición de economía social, creemos conveniente entenderla como varios autores y analistas de la economía social (v.g. Defourny, 1992, Gui 1991) han definido la misma como el tercer sector, ubicándose e incluyéndose en él las formas de organización económica que no casan ni en el sector capitalista ni en el sector público, es decir, las cooperativas, mutuas y asociaciones que cumplen funciones económicas sin ánimo de lucro. Opinamos que siguiendo el criterio de Rock y Klinedinst (1994) el incluir en la economía social partidos, grupos de interés, lobbies o sindicatos tal y como Barea (1991), Barea y Monzón (1992) o Michelsen (1994) apuntaron, sería un error ya que su finalidad y actividad principal no es económica y podría difuminar el sentido del tercer sector como forma diferenciada al sector capitalista y al público.

${ }^{6}$ Pettit, P. (1999). Republicanismo. Barcelona: Paidós. 
Sin embargo, el mayor o menor alcance de la economía social siempre y cuando éste esté establecido bajo los parámetros de mercado, no evita que una vez más nos encontremos con un modelo económico que deja de lado una gran parte del trabajo que no se rige bajo las mismas reglas.

Tal y como recientemente acaban de hacer Raventós y Wark (2016), el trabajo se puede separar en tres partes: trabajo remunerado, trabajo doméstico y trabajo voluntario. Así, podemos observar como el trabajo remunerado (o empleo u ocupación, como se conoce frecuentemente) y el trabajo voluntario entran dentro de los parámetros de la economía social, pero no así el trabajo doméstico. Más allá de que el trabajo doméstico no se contabilice a la hora de calcular los parámetros de crecimiento de un país, siendo el PIB la variable que normalmente se utiliza para medir los precios de mercado de los bienes y servicios finales producidos en un área geográfica determinada, en el mismo artículo anteriormente citado de Raventós y Wark (2016) se muestra como en varias estimaciones empíricas realizadas en diferentes países se observa que el porcentaje de trabajo doméstico respecto al PIB fluctúa entre la mitad y dos tercios del mismo.

"El problema radica en la manera en que se ha definido el «trabajo«, lo mismo en la teoría que en las estadísticas tradicionales, como una actividad económica remunerada vinculada al mercado». ${ }^{7}$

Así, observamos como la economía social no incluye en su conjunto todo tipo de trabajo y creemos que para que su papel socializador dentro del colectivo tenga validez en el seno de toda la ciudadanía y englobe todo trabajo que se realice en la misma, es necesario, si la manera de calcular el PIB no cambia, que ésta introduzca el trabajo doméstico dentro de su ámbito de protección social pese a que no se rija por las reglas del mercado.

¿Qué consecuencias acarrearía una renta básica incondicional en el seno del trabajo doméstico? La filósofa y escritora inglesa Mary Wollstonecraft (1759-1797) comentó en el siglo xvin que la conquista de derechos, ciudadanía y un mejor estatus para las mujeres se hallaba en lo que era su leitmotiv, la libertad económica de las mismas (Burdiel, 1999). Además, muchas mujeres que estén bajo el yugo de la trampa de la pobreza, con una renta básica podrían escapar de la misma y obtener su libertad económica, quedando así «la feminización de la pobreza enormemente mitigada» (Raventos y Wark, 2016).

7 Benería, L. (1999). El debate inconcluso sobre el trabajo no remunerado. Revista internacional del trabajo, 118 (3), 321-346. 
Es cierto que el trabajo doméstico no recae $100 \%$ sobre la mujer pero no hay duda de que las diferencias de trabajo doméstico soportadas entre ambos sexos son claras y, lo que es más preocupante, persistentes. En España y basándonos en los datos de las Encuestas de Empleo del Tiempo de 2003 y 2010 apreciamos cómo los hombres en situación laboral activa dedicaron en 20039,4 horas a la semana de media en labores domésticas y las mujeres, 34,7. En 2010 los números no varían mucho y mientras los hombres dedicaron 11,6 horas, las mujeres 31,12 (INE, 2011).

Tal y como pasa con el aumento en el poder de negociación de los trabajadores remunerados si recibieran una renta básica incondicional, podríamos afirmar que las personas sobre las que recaiga trabajo doméstico y en especial las mujeres, también tendrían un aumento en su poder de negociación. Al fin y al cabo, la renta básica dotaría de unos ingresos al trabajador doméstico, consiguiendo así su libertad al no depender de nadie más que de sí mismo.

\section{Conclusión}

Tras haber realizado un intento de análisis conjunto entre economía social y la renta básica incondicional desde distintas características en las que ambas difieren respecto al modelo neoliberal dominante en la economía mundial del siglo xxI, opinamos que habría que realizar una relación profunda que por falta de espacio y tiempo no ha sido posible realizarla en este artículo entre este modelo económico y esta medida económica. Una relación más intensa en la que podamos apreciar si realmente la renta básica incondicional sería una medida adecuada para implantarla dentro de un modelo económico donde predomine la economía social.

La primera relación que hemos hecho entre la economía social y la renta básica incondicional es el grado de alcance de ambas frente a los valores individualistas promulgados por el neoliberalismo. Aquí hemos observado cómo, a pesar de que ambos dejan atrás la atomización individualista de la sociedad, el ámbito de actuación de la renta básica incondicional es mayor al de la economía social. Mientras la economía social atomiza la sociedad en distintos agentes compuestos por un colectivo que se implica en su definición de objetivos y gestión interrelacionados por el mismo modelo productivo, el ámbito de actuación de la renta básica incondicional corresponde a toda la ciudadanía y los residentes dentro del área geográfica donde esté introducida.

Inmediatamente después, al intentar analizar el comportamiento de la economía social frente al estado hemos visto que mientras ésta se basa en el no intervencionismo del estado en la economía, la renta básica incondi- 
cional ve necesario que éste sea el intermediario a la hora de garantizar la redistribución de la riqueza para que la medida pueda ser acometida. Para que se dé la realización del principio de maximin de las condiciones materiales y los recursos sean redistribuidos de manera eficiente, es necesaria la intervención del estado y entender su actuación no como una sustracción de poder, sino como un simple intermediario para que el derecho a la existencia y a la libertad de todos los ciudadanos quede garantizado.

A la hora de analizar la economía social respecto al papel de la ciudadanía frente a la necesidad de participar activamente en la economía, vemos cómo para la realización de su objetivo es necesaria la implicación de la ciudadanía en la misma. Por el contrario, si un ciudadano, basándose en el derecho de la no participación, decidiera no participar activamente en la economía y no ser miembro de un nuevo mercado de intercambios solidarios, quedaría fuera de toda protección directa que la economía social ofrece a sus miembros. Aquí el ámbito de actuación de la renta básica incondicional también es mayor, ya que la libertad y el ejercicio de ciudadanía no están vinculados a la implicación en la economía, sino al derecho a la existencia bajo la eliminación del dominium ejercido sobre los ciudadanos que no son libres.

Finalmente, cuando hemos examinado los tipos de trabajo que se incluyen en la economía social, nos hemos percatado de que al igual que el modelo hegemónico hoy en día, se olvida del trabajo doméstico. La economía social supera solo parcialmente la ecuación de trabajo igual a empleo remunerado, añadiéndole el trabajo voluntario y englobando así aquellos agentes en los que su razón de ser radica en la producción de bienes y servicios. Sin embargo, el trabajo doméstico queda una vez más olvidado al no regirse por las reglas de mercado establecidas. En este punto no hay duda de que la renta básica va mucho más allá de la ecuación trabajo igual a empleo remunerado y garantiza la existencia material de aquellos ciudadanos olvidados por la mayoría de modelos económicos y por las políticas económicas que se están aplicando en los estados de bienestar en el siglo XXI. Desde nuestro punto de vista, la economía social debería abrir un nuevo apartado donde, pese a que no se rija por las reglas de mercado, tenga en cuenta la producción de servicios realizados bajo el concepto de trabajo doméstico. Así, creemos que la protección social que pueda ofrecer sería más amplia, reflejando y valorando aquellos trabajos olvidados dentro de las reglas de mercado tradicionales.

Lo que podemos afirmar una vez examinado este intento de relación es que la economía social pone su foco de atención en la fuerza socializadora que pueda tener mediante la condición de pertenencia del ciudadano y mediante la cercanía entre la economía y la sociedad civil, invitando a la implicación y creando una estrecha conexión entre ambas mediante la partici- 
pación. Sin embargo, la renta básica incondicional se centra en su principal objetivo de dotar de total libertad a todos los ciudadanos basándose en el derecho de no-dominación, para así poder conseguir la ciudadanía plena.

Somos de la firme convicción de que ambos objetivos son altamente deseables y para nada contrapuestos. Al contrario, la economía social y la renta básica incondicional son complementarios por su mayor alcance en conjunto, para así discurrir hacia una sociedad más justa basada en el maximin de las condiciones materiales, en la desaparición de la deshumanización existente y donde los ciudadanos puedan implicarse en la definición de objetivos y gestión de los agentes pertenecientes a la economía y donde el derecho a la existencia sea una realidad, no dependiendo de nadie más que de sí mismo para vivir dignamente.

\section{Bibliografía}

Arcarons, J., Domenech, A., Raventós, D. y Torrens, L. (2014). Un modelo de financiación de la Renta Básica para el conjunto del Reino de España: sí, se puede $y$ es racional. [online]. SinPermiso. Disponible en: http://attac-catalunya.cat/ download/alternatives/Modelo\%20de\%20Renta\%20b\%C3\%A1 sica\%20 para\%20el\%20Reino\%20de\%20Espa\%C3\%B1a.pdf [Accedido el día 4 de mayo de 2016].

Barea, J. (1990). Concepto y agentes de la Economía Social. CIRIEC-España, Revista de Economía Pública, Social y Cooperativa. 8, pp. 109-117.

Barea, J. (1991). La economía social en Espańa. Economía y sociología del trabajo, 12, pp. 8-16.

Barea, J. y Monzón, J. L. (1992). La economía social en España. En: J. L. Monzón y J. Defourny (Eds) Economía Social. Entre economía capitalista y economía pública. Valencia: CIRIEC-España.

Bertomeu, M.J. y Raventós, D. (2006). El derecho de existencia y la renta básica de ciudadanía: una justificación republicana. En: La renta básica como nuevo derecho ciudadano, pp. 19-34. Madrid: Trotta.

Bourdieu, P. (1998). La esencia del neoliberalismo. Paris: Le monde diplomatique.

Burdiel, I. (1994). Mary Wollstonecraft. Vindicación de los derechos de la mujer. Madrid: Cátedra.

Caracuel, M. R. A., y Fernández, M. G. (1999). La seguridad social en España. Trabajo: Revista andaluza de relaciones laborales, 7, pp. 285-289.

Carpi, J.A.T. (1997). La Economía Social en un mundo de transofrmación. CIRIEC-España, Revista de Economía Pública, Social y Cooperativa. 25, pp. 83115.

Casassas, D. y Raventós, D. (2011). La renta básica en la era de las grandes desigualdades. Barcelona: Montesinos.

Ciriec (2000). Economía Social y empleo en Europa. Valencia: Ciriec España. 
Coraggio, J.L. (2011). Economía Social y Solidaria. El trabajo antes que el capital. Quito: Abya-Yala.

Defourny, J. (1992). Orígenes, contextos y funciones de un tercer gran sector. En: J.L. Monzón, y J. Defourny (Eds.) Economía social. Entre economía capitalista y economía pública. Valencia: CIRIEC-España, pp. 227-262.

Domenech, A. (2007). Prólogo. En: D. Raventós. Las condiciones materiales de la libertad. Barcelona: El Viejo Topo.

Elster, J. (1982). Roemer versus Roemer. Politics and Society, 11(3), pp. 363-374.

Etzioni, A. (2013). El guardian de mi hermano: autobiografia y mensaje (Vol. 30). Madrid: Palabra.

França Filho, G. C. D. (2002). Terceiro setor, economia social, economia solidária e economia popular: traçando fronteiras conceituais. Bahia Análise \& Dados, 12 (1), pp. 9-19.

França Filho, G., y Dzimira, S. (2000). Don et économie solidaire: esquisse d'une théorie socio-économique de l'économie solidaire. Paris: La Découverte.

Francisco I. (2013). Evangelii Gaudium. [online] Vatican. Disponible en: http:// w2.vatican.va/content/francesco/es/apost_exhortations/documents/papa-francesco_esortazione-ap_20131124_evangelii-gaudium.html. [Accedido el día 4 de mayo de 2016].

Gómez, M.V. (2016). La "hucha de las pensiones» acaba 2015 con menos de la mitad que en 2014. El País.

Gui, B. (1991). The economic rationale for the "Third Sector». Annals of public and cooperative economics, 62 (4), 551-572.

Hirschman, A.O. (1970). Exit, voice, and loyalty: Responses to decline in firms, organizations, and states. Cambrige, MA: Harvard University Press.

Hirschman, A.O. (1987). The political economy of Latin American development: seven exercises in retrospection. Latin American Research Review, 22 (3), pp. 7-36.

Instituto Nacional de Estadística (2004). Encuesta de Empleo del Tiempo 20022003. Instituto Nacional de Estadistica. [online] Disponible en: http://www. ine.es/daco/daco42/empleo/dacoeet.htm [Accedido el día 17 de mayo de 2016].

Instituto Nacional de Estadística (2011). Encuesta de Empleo del Tiempo 20092010. Instituto Nacional de Estadística. [online] Disponible en: http://www.ine. es/dyngs/INEbase/es/operacion.htm?c=Estadistica_C\&cid=1254736176815\& menu=resultados\&idp=1254735976608 [Accedido el día 17 de mayo de 2016].

Michelsen, J. (1992). El mercado, el estado del bienestar y el sector de la economía social. El caso de Dinamarca. En: J.L. Monzón, y J. Defourny (Eds.) Economía social. Entre economía capitalista y economía pública. Valencia: CIRIECEspańa, pp. 227-262.

Michelsen, J. (1994). The rationales of cooperative organizations. Some Suggestions from Scandinavia. Annals of public and cooperative economics, 65 (1), 13-34. 
Oxfam (2016). Una Economía al Servicio del 1\%. [online] Oxfam International. Disponible en: https:/www.oxfam.org/sites/www.oxfam.org/files/file_attachments/bp210-economy-one-percent-tax-havens-180116-es_0.pdf [Accedido el día 2 de mayo de 2016].

Paine, Thomas (1976). Agrarian Justice. En: P.F. Foner (Ed.) The Life and Major Writings of Thomas Paine. Secaucus, N.J.: Citadel Press, pp. 605-623.

Petit, P. (1997). Republicanism. Oxford: Clarendon Press.

Pocock, J. G. A. (1975). The Machiavellian Moment: Florentine Political Thought and the Atlantic Republican Tradition. Princetonn, NJ: Princeton University Press.

Raventós, D. y Wark, J. (2016). Trabajo remunerado, trabajo doméstico, trabajo voluntario y Renta Básica. Red Renta Básica, [online]. Disponible en: http:// www.redrentabasica.org/rb/trabajo-remunerado-trabajo-domestico-trabajo-voluntario-y-renta-basica/ [Accedido el día 10 de mayo de 2016].

Rawls, J. (1993) Political Liberalism. New York: Columbia University Press

Red Renta Básica (s.a.). ¿Qué es la RB? [online] Disponible en: http://www.redrentabasica.org/rb/que-es-la-rb/ [Accedido el día 4 de mayo de 2016].

Rock, C. y Klinedinst, M. (1994). L 'économie sociale aux Etats-Unis: les critères et les organisations. Revue des Etudes Cooperatives, Mutualistes et Associatives, 253(4), pp. 51-2.

Rosanvallon, P. (1995). La nueva cuestión social: repensar el estado providencia. Buenos Aires: Ediciones Manantial.

Skinner, Q. (1992). About Justice, the Common Good and the Priority of Liberty. En: C. Mouffe (Ed.) Dimensions of Radical Democracy. Londres: Verso.

Van Parijs, P. (1995). Real Freedom for All, What (if anything) can justify capitalism. Clarendon Press, Oxford.

Van Parijs, P. (1996). Justice and democracy: are they incompatible? Journal of Political Philosophy, 4, pp. 101-117. 